\title{
TRANSTORNO DE PERSONALIDADE PARANÓIDE PRÉ MÓRBIDO NO TRANSTORNO DELIRANTE: UM ESTUDO DE CASO
}

\author{
Helena Chibani Mauad ${ }^{1}$ \\ Juliana Marim² \\ Luiz Fernando Ribeiro da Silva Paulin ${ }^{3}$ \\ Ana Luiza Novaes Ribeiro 4 \\ Mellina Stoianov Rocha ${ }^{5}$ \\ Gabrielly Silva Santos 6
}

RESUMO: Transtornos da personalidade do grupo A freqüentemente são condições prémórbidas ou comórbidas de Esquizofrenia e Outros Transtornos Psicóticos. Observa-se na literatura maior associação dos Transtornos da Personalidade Esquizotípica e Paranóide com o desenvolvimento da Esquizofrenia. Enquanto isso, alguns estudos apontam associação entre antecedente familiar de Transtornos da Personalidade Paranóide e Evitativa e o desenvolvimento de Transtorno Delirante. O presente estudo tem por objetivo relatar um caso de Transtorno da Personalidade Paranóide pré-mórbido evoluindo para Transtorno Delirante em um paciente adulto, do sexo masculino, com prejuízos sociais em decorrência tanto da personalidade paranóide como da reagudização do quadro delirante, a despeito da manutenção de funções cognitivas. Além disso, o relato propõe o estabelecimento de diagnósticos diferenciais com Transtornos da Personalidade Esquizóide e Narcisista e com a Esquizofrenia. Este estudo se fundamenta em uma base de dados que inclui artigos de periódicos, relatos de casos, compêndio de Psiquiatria e Manual Diagnóstico e Estatístico de Transtornos Mentais.

Palavras-chave: Transtorno De Personalidade Paranóide. Transtorno De Personalidade. Transtorno Delirante e Esquizofrenia.

ABSTRACT: Group A personality disorders are often premorbid or comorbid conditions of Schizophrenia and other psychotic disorders. A greater association of Schizotypical and Paranoid personality disorders with the development of Schizophrenia is observed in the literature. Meanwhile, some studies show an association between a family history of Paranoid and Avoidant Personality Disorders and the development of Delusional Disorder.

\footnotetext{
I Curso: Residência médica de Psiquiatria. Instituição: Hospital Universitário São Francisco. E-mail: helenacmauad@gmail.com.

${ }^{2}$ Curso: Medicina. Instituição: Universidade São Francisco.

${ }^{3}$ Curso: Medicina. Instituição: Universidade São Francisco.

${ }^{4}$ Curso: Residência médica de Psiquiatria. Instituição: Hospital Universitário São Francisco.

5 Curso: medicina. Instituição: Universidade São Francisco.

${ }^{6}$ Curso: medicina. Instituição: Universidade São Francisco.
} 
The present study aims to report a case of premorbid Paranoid Personality Disorder evolving to Delusional Disorder in an male adult patient, with social damage due to both the paranoid personality and the worsening of the delusional condition, despite the maintenance of cognitive functions. In addition, the report proposes the establishment of differential diagnoses with Schizoid and Narcissistic Personality Disorders and with Schizophrenia. This study is based on a database that includes journal articles, case reports, Psychiatry compendium and Diagnostic and Statistic Manual of Mental Disorders.

Keywords: Paranoid personality disorder. Personality disorder. Delusional disorder. Schizophrenia.

\section{INTRODUÇÃO}

O Transtorno de Personalidade Paranóide consiste em um padrão generalizado de desconfiança e suspeitas injustificadas de outros. Ocorre mais comumente em indivíduos do sexo masculino. Suas características marcantes são modos formais, afeto restrito, discurso lógico e pensamentos com conteúdo auto-referentes, bem como o questionamento de lealdade e integridade alheias. Diferencia-se do Transtorno Delirante majoritariamente devido à ausência de delírios fixos. O Transtorno Delirante, por sua vez, é caracterizado pela presença do sintoma-chave de delírio lógico e sistematicamente elaborado. Costuma

cursar sem deterioração da personalidade ou déficit na maioria das áreas de funcionamento e o prejuízo funcional costuma ser mais circunscrito que o encontrado em outros transtornos psicóticos, ainda que possa ser substancial em alguns casos, incluindo funcionamento profissional insatisfatório e isolamento social. Quando um funcionamento psicossocial insatisfatório está presente, as próprias crenças delirantes costumam ter papel importante nesse desfecho. Uma característica comum dos indivíduos com transtorno delirante é a aparente normalidade de seu comportamento e aparência quando não estão sendo discutidas ou acionadas suas idéias delirantes.

Estudos mostram que, se encarados dentro de uma ótica espectral, os transtornos psicóticos podem apresentar transtornos de personalidade como condições pré-mórbidas ou até mesmo comórbidas. Apesar da associação mais encontrada em literatura ser o transtorno de personalidade esquizotípica e paranóide evoluindo para esquizofrenia, outros desfechos são observados na prática clínica, os quais permitem o fomento de novas investigações diagnósticas e terapêuticas. 
O caso ilustra este cenário alternativo, com a evolução de um Transtorno de personalidade paranóide para Transtorno delirante. Havia extenso histórico de prejuízos no funcionamento psicossocial e profissional em decorrência do transtorno de personalidade paranóide. Eram marcantes as dificuldades na formação de vínculos pessoais e de trabalho em decorrência de desconfianças e receio de ser enganado, ocasionando diversas vezes em conflitos e pedidos de demissão por motivos injustificados. Entretanto, havia manutenção das funções cognitivas. A evolução culminou com quadro delirante estruturado e sistematizado, com angústia, agitação e ideação suicida persistente, necessitando de intervenção psiquiátrica imediata.

Esta pesquisa foi aprovada no comitê de ética e pesquisa da instituição sob o parecer 46749821.9.00oo.5514 e objetiva descrever a associação incomum entre o Transtorno da Personalidade Paranoide com o Transtorno Delirante e seus desfechos, dando destaque para a Síndrome de Capgras, que consiste na crença delirante de que um indivíduo foi substituído por outro fisicamente idêntico a outro, mas preservando as características psicológicas deste "impostor".

Através da associação supracitada, esse relato propõe a reflexão acerca dos Transtornos da Personalidade do cluster A enquanto condição pré-mórbida e comórbida de Transtornos Psicóticos, bem como as conseqüências psicossociais de tais associações. Além disso, o relato traz como destaque uma ramificação do Transtorno Delirante do tipo persecutório: a síndrome de Capgras ou a ilusão de sósias.

\section{METODOLOGIA}

Trata-se de um relato de caso de um paciente tratado em enfermaria psiquiátrica de hospital geral, o qual foi descrito através de anamnese psiquiátrica habitual, que é composta por identificação do paciente, entrevista com paciente e familiar, história da moléstia atual, antecedentes pessoais, histórico familiar, exame físico geral e exames complementares (laboratoriais e de imagem). Identificadas as patologias e devido à raridade dos eventos, o relato foi sucedido por uma revisão bibliográfica acerca do tema para que fosse mais bem elucidado. Este estudo foi realizado com base no levantamento de dados bibliográficos nos bancos de dados PUBMED, SCIELO, LILACS e RIMA, a partir dos descritores: 
“transtorno de personalidade paranóide”, "paranoid personality disorder”, "transtorno de personalidade”, “personality disorder", "transtorno delirante”, “delusional disorder", "esquizofrenia" e "schizophrenia". Além disso, foi realizada análise dos dados do paciente do relato.

\section{RELATO DE CASO}

Paciente 42 anos, masculino, divorciado, com ensino superior completo (ciência da computação), além de fluência em Inglês e Francês, encaminhado de ambulatório de psiquiatria municipal por quadro delirante há 3 meses, com piora há 2 semanas.

Paciente relata desde a adolescência um padrão generalizado de desconfianças e medo de ser prejudicado e julgado. Relata que também possuía o costume de julgar pessoas baseado em aparência, comportamento e discurso. Por este motivo, sempre teve poucos relacionamentos interpessoais. Nunca possuiu amigos e não sentia falta de tê-los, e apenas sua ex-esposa não lhe despertava desconfianças. Trabalhava em empresa multinacional de tecnologia e softwares, onde sempre apresentou conflitos de trabalho devido a julgamentos e desconfianças alheias.

Iniciou tratamento psiquiátrico em 2004, relatando sentir-se deprimido, porém nitidamente como conseqüência de seu padrão de comportamento. Iniciou tratamento psicofarmacológico com uso de bupropiona, porém sem melhora significativa de sintomas de tristeza, anedonia e irritabilidade. Dois anos depois, foi enviado pela empresa para trabalhar no escritório na França, onde sua esposa residia. Apesar de encontrar nela seu único vínculo afetivo e de confiança, teve um relacionamento extraconjugal com colega de trabalho. Relata que sua esposa eventualmente descobriu, e que desde então o relacionamento deteriorou-se. Procurou continuar o tratamento psiquiátrico na França, sendo que a medicação foi trocada para paroxetina, com melhora dos sintomas de tristeza e anedonia, mas mantendo sempre padrão de desconfiança injustificada, medo de julgamento alheio, por vezes culminando em conflitos de trabalho.

Esta situação foi piorando progressivamente, sendo que na época em que completava um ano na filial francesa, seus sintomas agravaram-se significativamente, cursando com crise de alteração de comportamento, tendo como desencadeantes ideias persecutórias com 
colegas de trabalho e antiga relação extraconjugal. Acreditava ser prejudicado por um colega de trabalho específico, e em determinado momento chegou a crer que ele estava se passando por seu chefe, justificando que o chefe passou a ter trejeitos e modos de falar iguais aos deste colega. Também cogitou que seu psiquiatra estivesse envolvido em trama para minar sua reputação, no entanto, acabou descartando a idéia e aceitou a associação de olanzapina prescrita por ele. Houve remissão do quadro delirante, porém não de seu comportamento prévio.

A postura de hostilidade propagou-se para o resto da empresa, de modo que, mesmo com remissão do quadro delirante, as relações profissionais tornaram-se extremamente desgastadas. Além disso, relata piorar consumo de tabaco ( 3 maços de cigarro por dia) e iniciar etilismo, o qual se tornou rapidamente muito intenso (I litro de destilado ao dia), chegando a beber inclusive durante o trabalho. Segundo seu pai, esse etilismo se propagou por mais alguns anos, cessando em 2016. O paciente esteve abstinente desde então.

Refere que pediu demissão em 2012 devido às "relações desgastadas", permanecendo na França por mais dois anos vivendo com seguro-desemprego. No entanto, contraiu muitas dívidas e desenvolveu problemas fiscais, sendo processado pelo Estado. Esta situação, associada ao casamento desgastado, culminou em seu divórcio e volta para o Brasil em 2014, quando perdeu seguimento psiquiátrico.

Foi morar na chácara dos pais no interior, que o visitavam aos finais de semana. Preferia ficar isolado, pois acreditava que familiares o julgavam por estar desempregado e viver à custa dos pais. Relata uma nova tentativa de emprego na sua área de atuação entre 2017 e 2018, com mesmas dificuldades nos relacionamentos com os colegas de trabalho, crendo que os mesmos tinham interesses escusos, além disso, irritava-se perante possíveis julgamentos. Pediu demissão devido a esses motivos, e desde então não conseguiu outro emprego.

Teve algumas consultas com psiquiatra da rede, que prescreveu escitalopram is $\mathrm{mg}$ e Risperidona $2 \mathrm{mg}$, os quais o paciente fez uso irregular.

Há 3 meses começou a perceber "câmeras de segurança” na rua voltados para sua casa e aumento das luzes na rua. Pai relata que tentou montar lâmpadas no jardim, e que o paciente questionava se estavam ali por conta de algum tipo de "ritual". O paciente chega a 
questionar-se se essas mudanças ocorreram devido a uma tentativa de assalto a sua chácara alguns meses antes, mas acredita que estejam acontecendo para monitorizar suas atividades.

Há 2 semanas, relata que percebeu que sua internet foi hackeada. Seu pai relata que o mesmo chegou a desmontar o computador para encontrar alguma peça adicionada ao mesmo. Conta que notícias de jornais que assina do Brasil, França e Inglaterra foram alteradas de modo que continham mensagens especialmente direcionadas a ele. Refere que entende que não é uma pessoa de interesse especial para nenhuma organização nacional ou internacional, mas tem receio que esteja sob investigações governamentais devido às dívidas que contraiu na França.

Procurou o serviço de psiquiatria da rede devido angústia crescente frente aos sintomas. Relata não conseguir dormir, perder peso, sentindo-se ameaçado e muito preocupado, pois segundo ele, “sabe que seu juízo de realidade não é confiável”. Chegou a tentar fugir à pé, sendo encontrado dias depois pela família, perambulando por rodovia próxima a sua residência. Tinha ideação suicida fixa e estruturada, envolvendo trancar-se no banheiro e aspirar monóxido de carbono. Questiona se os eventos que está vivendo são reais devido à crítica parcial, mas sente que os são, embora não consiga explicar com argumentos lógicos.

Devido ao risco de suicídio, foi indicada internação em enfermaria psiquiátrica, onde foi suspenso o escitalopram e mantida a Risperidona 2 mg I cp à noite, aumentado durante a internação para I cp de 12/12h. Além disso, foi introduzido prometazina $25 \mathrm{mg}$ Icp à noite para indução do sono.

Paciente permaneceu internado pelo período de três semanas, onde evoluiu com melhora da angústia, da insônia e da persecutoriedade, relatando que está preparado para enfrentar os problemas que está sofrendo. Transferido para continuidade do cuidado em hospital-dia, onde permaneceu mais duas semanas, evoluindo para alta para acompanhamento ambulatorial.

\section{DISCUSSÃO}

Os transtornos psicóticos, especialmente a Esquizofrenia, podem ser marcados pela presença de personalidades pré mórbidas. Esta observação costuma ser realizada em 
retrospectiva na prática clínica, no entanto, podemos fazer o caminho oposto, predizendo o risco de evolução para psicose nestes pacientes através de intervenções precoces. Em destaque, observa-se tanto na literatura quanto na prática clínica o Transtorno da personalidade esquizotípica ou paranóide antecedendo o início da Esquizofrenia.

Apesar de observarmos a correlação entre transtornos de personalidade e transtornos psicóticos, as psicopatologias relatadas neste caso (Transtorno de Personalidade Paranóide pré-mórbido evoluindo para Transtorno Delirante) enquanto condições comórbidas são escassas. Além disso, trazemos Transtorno Delirante cujo conteúdo é ainda mais raro: a Síndrome de Capgras, ou "delírio dos sósias".

Tanto o transtorno de personalidade paranóide como o transtorno delirante são condições subrelatadas, pois os indivíduos portadores destes quadros raramente buscam ajuda psiquiátrica, sendo muitas vezes trazidos por familiares, e freqüentemente abandonam o tratamento.

Chama-se a atenção para os prejuízos que essa subnotificação causa, pois o transtorno delirante, uma vez identificado e tratado de maneira correta, costuma ter bom prognóstico. No entanto, a associação com Transtorno de personalidade paranóide pode obscurecer o prognóstico, acarretando pior funcionalidade, menor qualidade de vida e inúmeros prejuízos psicossociais.

Portanto, o propósito deste relato é a contribuição acadêmica para este tema pouco explorado através de relatos de caso. Ademais, através deste estudo de caso é possível ilustrar os prejuízos psicossociais e funcionais que ambas as condições acarretam, destacando-se, assim, a necessidade de diagnóstico e intervenção precoce.

\section{BIBLIOGRAFIA}

ANGSTMAN, Kurt; RASMUSSEN, Norman H. Personality disorders: review and clinical application in daily practice. American family physician, v. 84, n. II, p. I253-I260, 20II.

DIEFENDERFER, Lauren A.; LANG, Shelby E.; PATEL, Maheshkumar. Successful Treatment of Delusional Disorder With Aripiprazole Long-Acting Injection. Journal of clinical psychopharmacology, v. 38, n. 4, p. 400-402, 2018. 
FIRST, Michael B. Manual de diagnóstico diferencial do DSM-5. Artmed Editora, 2014. HÖRZ-SAGSTETTER, Susanne et al. Clinical characteristics of comorbid narcissistic personality disorder in patients with borderline personality disorder. Journal of personality disorders, v. 32, n. 4, p. 562-575, 2018.

ISOPPO, Graziella Sanco de Lima. Terapia Focada em Esquemas e Personalidade Narcisista: um entendimento acerca deste transtorno. 2012.

IANNUZZI, Gregory L.; PATEL, Ankita A.; STEWART, Jonathan T. Aripiprazole and delusional disorder. Journal of Psychiatric Practice ${ }^{\circledR}$, v. 25, n. 2, p. 132-134, 2019.

JOINER JR, Thomas E. et al. Depressive symptoms induce paranoid symptoms in narcissistic personalities (but not narcissistic symptoms in paranoid personalities). Psychiatry research, v. 159, n. I-2, p. 237-244, 2008.

MEWS, Marie Rosa; QUANTE, Arnim. Comparative efficacy and acceptability of existing pharmacotherapies for delusional disorder: a retrospective case series and review of the literature. Journal of clinical psychopharmacology, v. 33, n. 4, p. 512-519, 2013.

MANSCHRECK, THEO C. Delusional disorder and shared psychotic disorder. Comprehensive Textbook of Psychiatry. 7th ed, Baltimore: Williams \&Wilkins, p. 1243I26, 2000 .

PANDIS, Charalampos; AGRAWAL, Niruj; POOLE, Norman. Capgras' Delusion: A Systematic Review of 255 Published Cases. Psychopathology, v. 52, n. 3, p. 16I-I73, 2019.

RONNINGSTAM, Elsa; WEINBERG, Igor. Narcissistic personality disorder: progress in recognition and treatment. Focus, v. II, n. 2, p. 167-177, 2013.

SALLET, Paulo Clemente; FRITZEN, Fabiele Maidel; FUKUDA, Lívia Emy. Síndromes Psicopatológicas: Transtornos Psicóticos Breves, Transtorno Esquizoafetivo e Transtorno Delirante.

VYAS, Amy; KHAN, Madiha. Paranoid personality disorder. American Journal of Psychiatry Residents' Journal, v. II, n. oI, p. 9-II, 2016. 